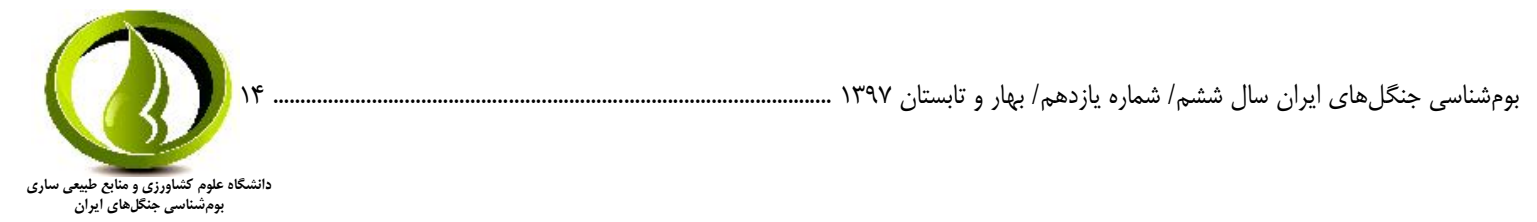

ارزيابى تنوع زنتيكى سروكوهى نواحى شمال ايران با استفاده از نشانكرهاى ISSR

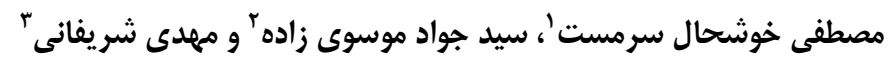

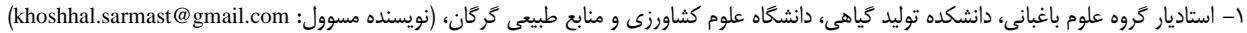

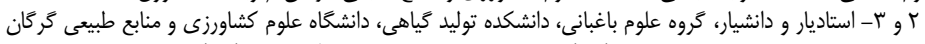

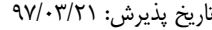
ت تاريخ دريافت:

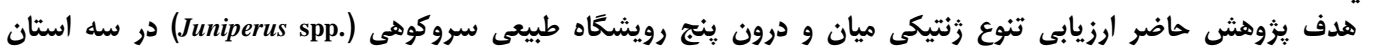

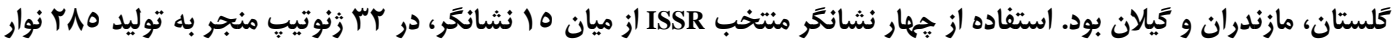

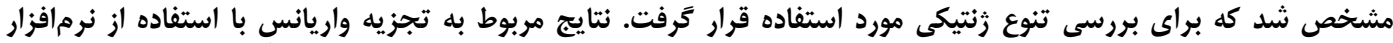
GeneAIEx

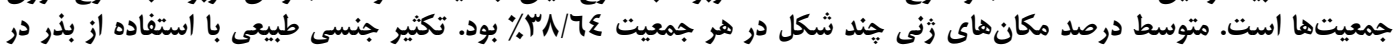

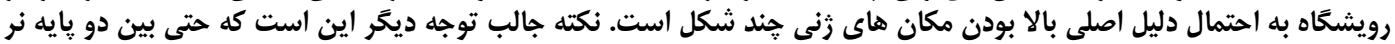

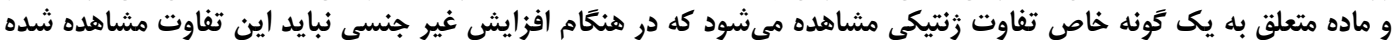

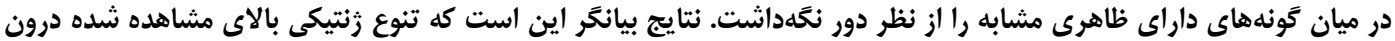

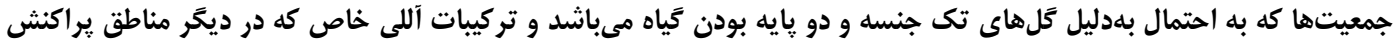

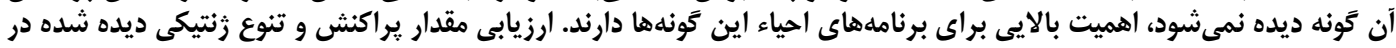

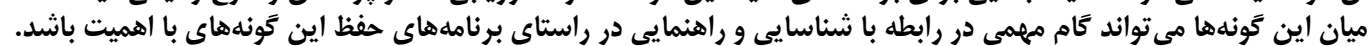

وازههاى كليدى: سرو كوهى، نشانكَرهاى مولكولى، تنوع زنتيكى، جند شكلى، ISSR

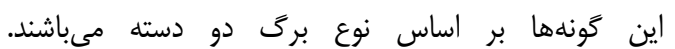

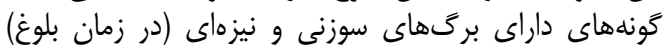

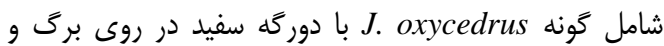

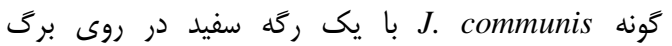

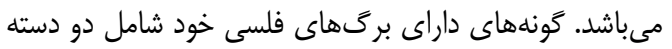

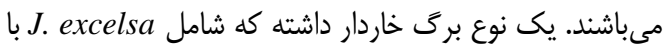
شاخههاى فرعى باريك و گرد و ديخرى

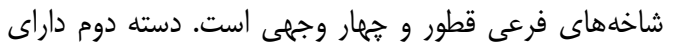

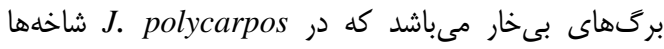

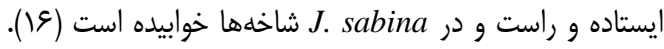

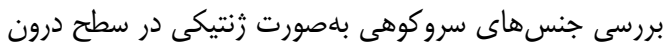

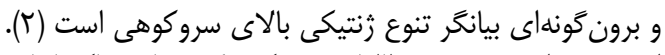

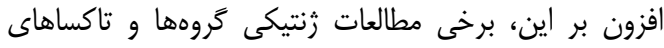

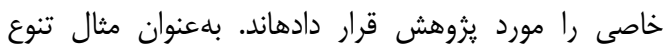

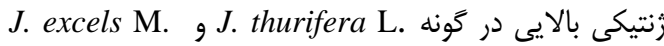

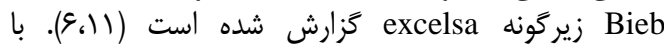

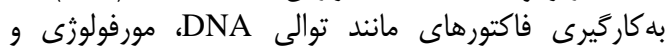
ترينوئيد برى مشخص شده است كه

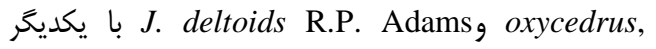
متفاوت هستند (ّ). اين تفاوت درست بهاندازهاى است كه

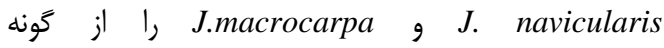
J. oxycedrus L. var oxycedrus,

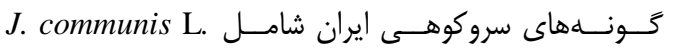
J. foetidissima ، J. sabina L.، J. oblonga M.B. أس Willd.

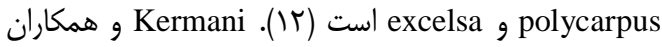

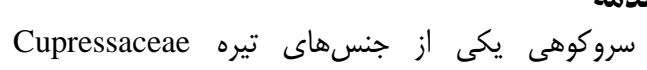

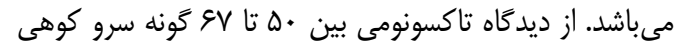

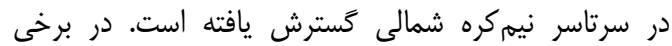

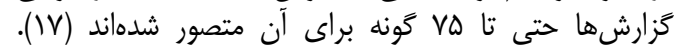

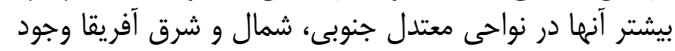

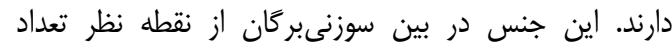

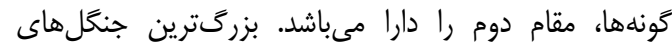

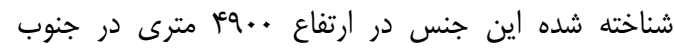

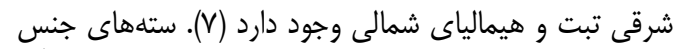

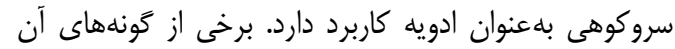

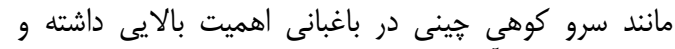

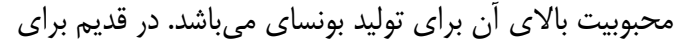

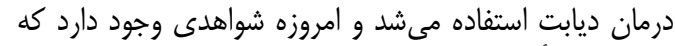

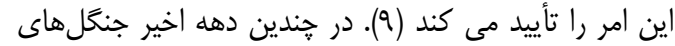

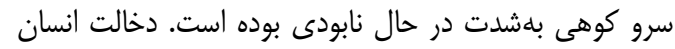

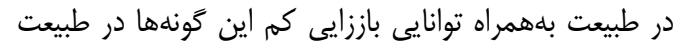

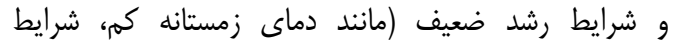

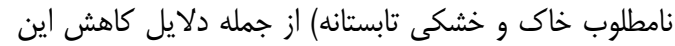

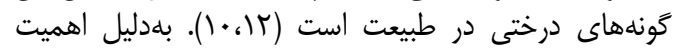

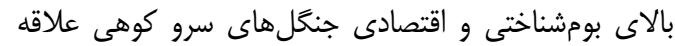

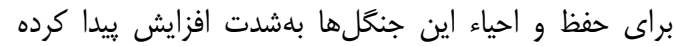

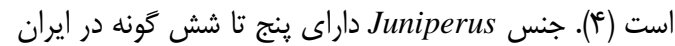

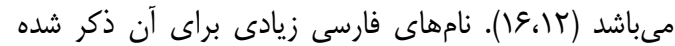

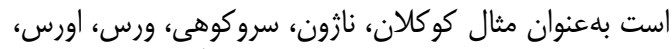
برس، وهل و سندروس برخى از نامهاى آن مى باشند 
غيرجنسى و همرجنين به حفظ گونههاى سرو كوهى و يِيشبرد بلنزادى اين كياه كمى كند.

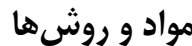

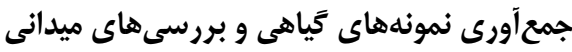

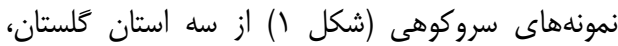

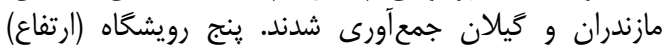

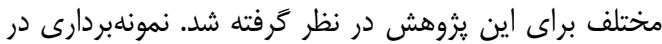

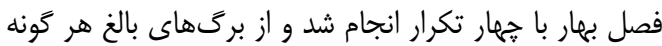

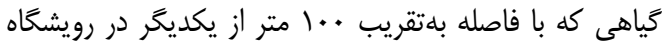

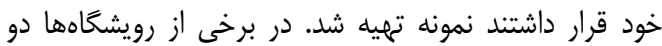

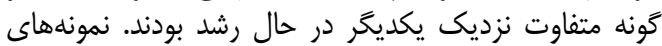

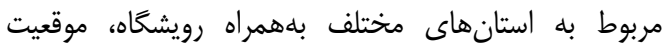

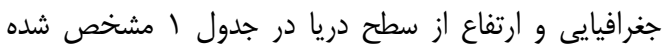

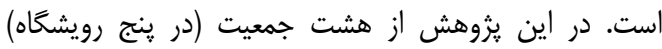

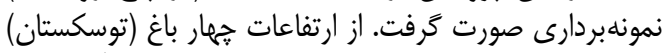

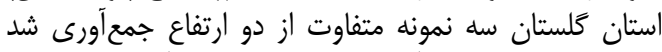

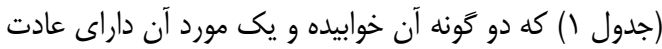

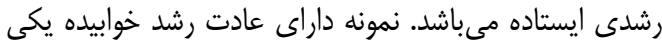
J. sabina

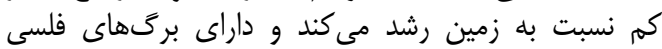

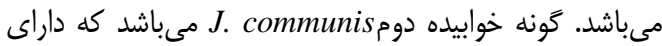

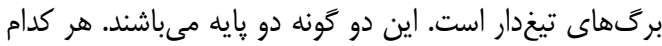

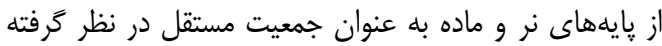

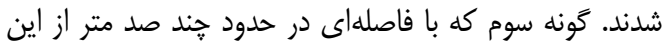

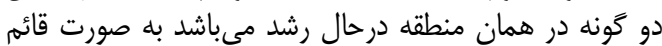

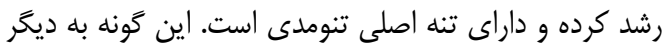

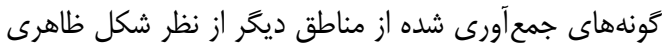

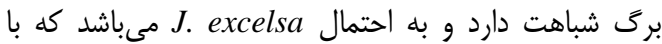

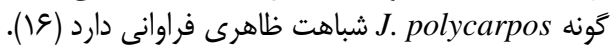

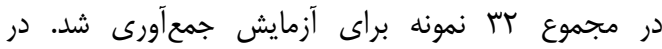

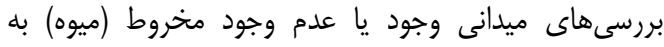

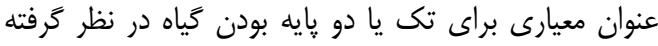

(זار) تنوع زنتيكى برخى از نمونههاى سروكوهى موجود در

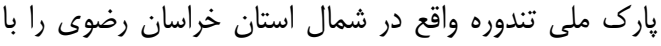

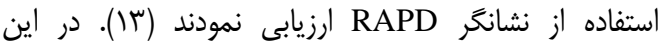

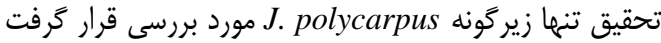

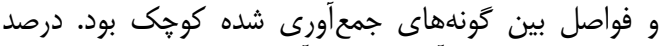

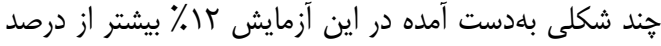

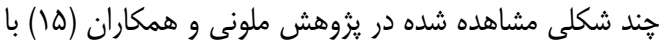

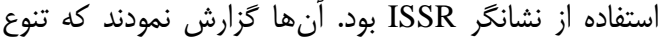

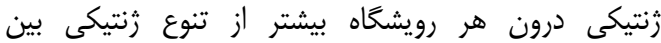

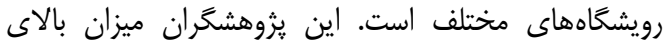

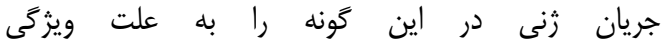
كل هاى تكىجنسه و دويايه بودن زيركّنه

بيان كردند.

بيشتر گونههاى يافت شده در شمال غرب ابر ايران و نواحى إنى

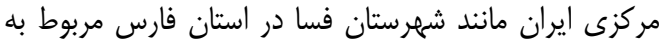
J. polycarpos

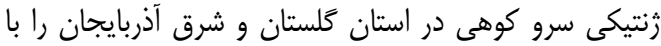
استفاده از نشانكر مولكولى RAPD مورد ارزيابى قرار دادني

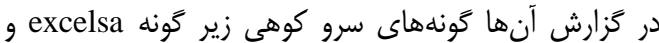
polycarpos

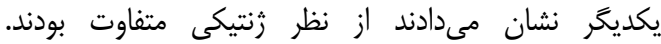

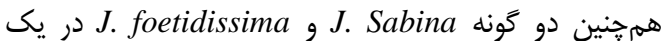

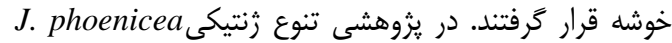

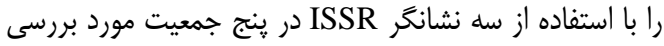

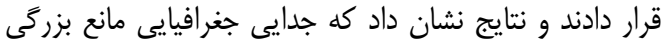

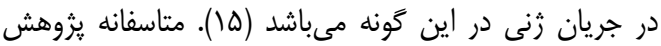

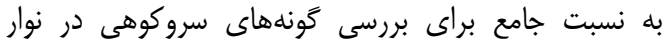

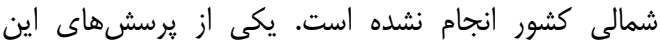

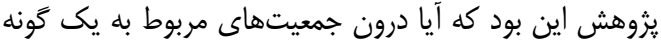

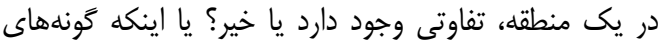

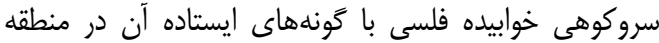

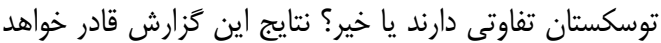

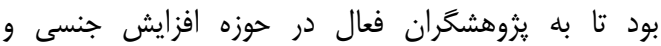

Table 1. Geographic position of Juniperus spp. collected from different provenance

\begin{tabular}{|c|c|c|c|}
\hline ارتفاع (متر) & موقعيت جغرافيايى & منطقه & استان \\
\hline THYA & 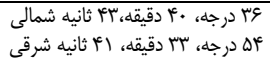 & توسكستان (سرييج على آباد) & 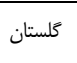 \\
\hline Tr. & 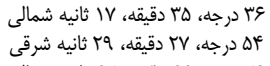 & קجهارباغ & 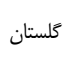 \\
\hline M. & 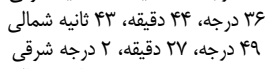 & هرزويل منجيل & كيلان \\
\hline IVEF & 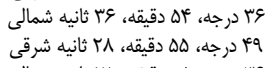 & ديلمان & كيلان \\
\hline$\Lambda .$. & 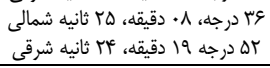 & جاده هراز & مازندران \\
\hline
\end{tabular}

روش تغيير داده شده از اسيد آسكوربيك و DNA استفاده نش DIECA براى

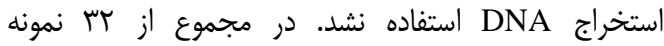

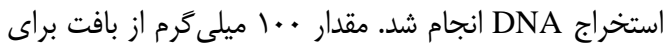

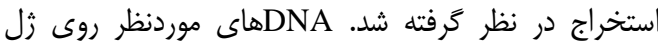

DNA بتخراج استخراج

براى استخراج DNA از روش استانت و همكاران (1)

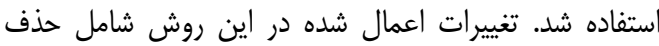
PVP 
ارزيابى تنوع زُنتيكى سروكوهى نواحى شمال ايران با استفاده از نشانكرهاى

حضور و حضور نوار DNA انجام شد. براى محاسبه فواصل

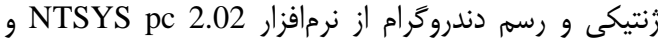

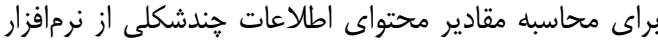
Excel 2003

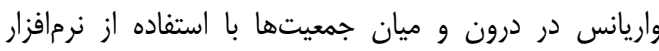
GeneAlEx

نتايج و بحث

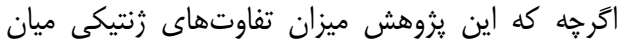

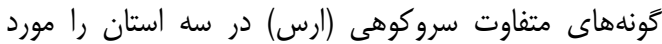

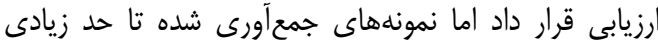

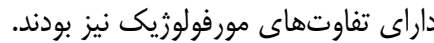

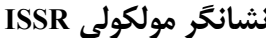

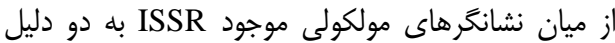

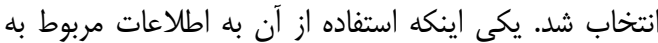

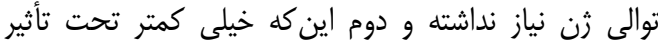

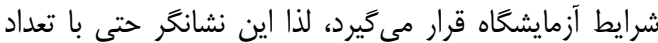

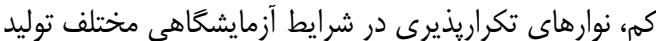
مي كند (10) (10)

تجزئُ بس نمونه سروكوهى جمع آورى شده از سه استان

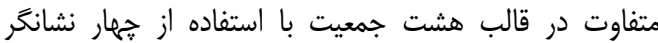

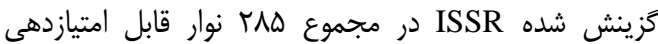

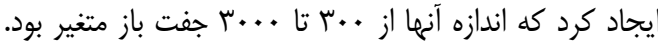

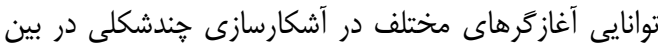

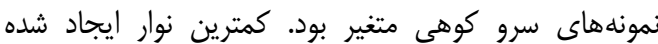

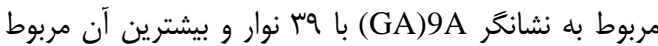

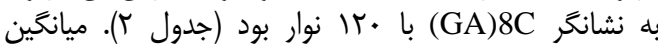

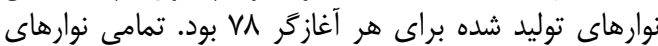

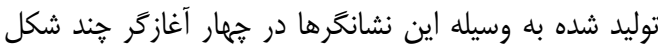

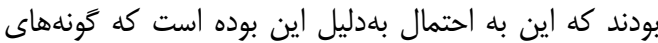

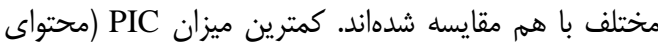

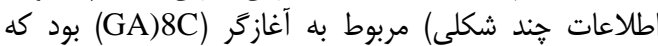

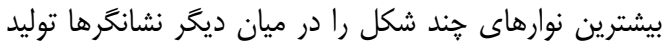

نمود (جدول r).
آَاروز ا ٪ براى بررسى كيفيت DNA رانده شدند و براى بلند

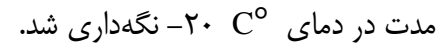
نشانك, مولكولى ISSR و انجام PCR از حدود ها نشانگر ISSR تهيه شده أندام از شركت متابيون

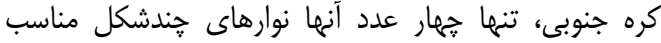

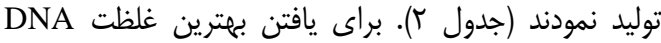

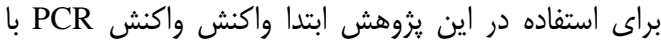

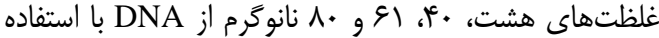

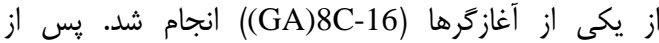

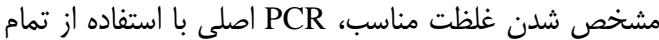

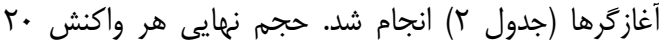

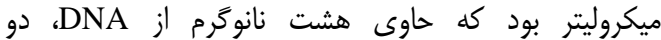

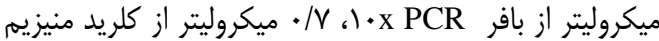

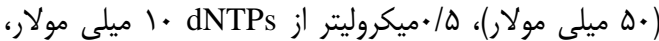

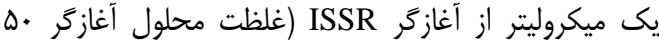

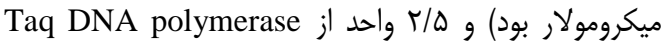

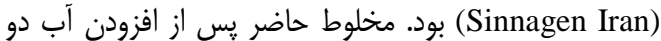

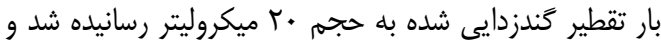

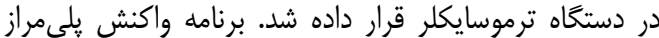

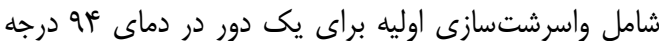
سانتى

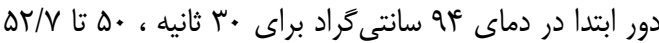

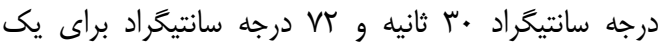

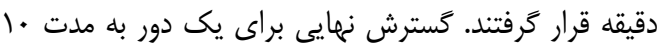

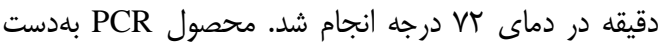

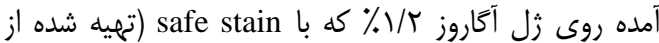

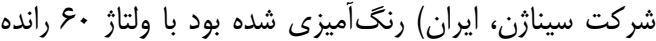

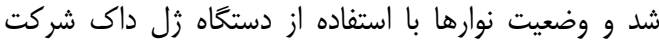

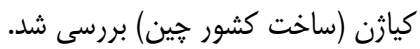

تجزيه و تحليل دادهها

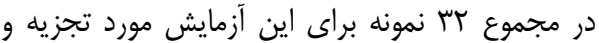

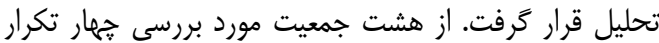

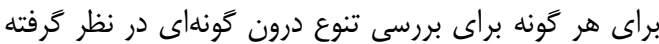

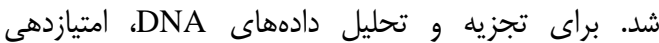
نوارهاى DNA به صورت (صفر) و (يك) بلهترتيب براى عدم

جدول r- نام، دما، تعداد مكان زنى و تعداد نوارهاى هُند شكل و محتواى اطلاعات هند شكلى توليد شده به وسيله آغازگرهاى ISSR براى

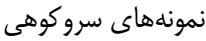

Table 2. Name, temperature, locus number, polymorphic bands and PIC of ISSR primers for Juniperus spp

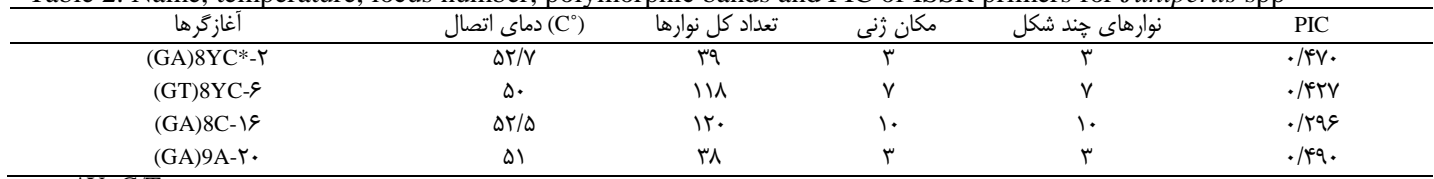




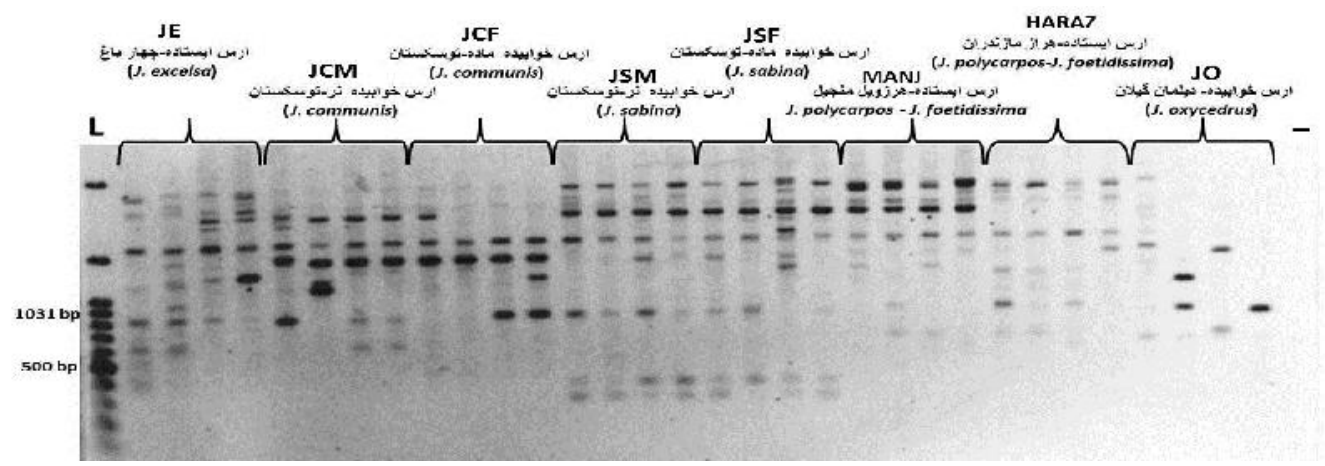

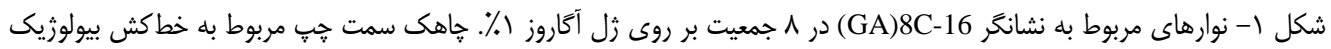

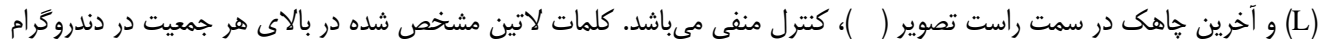

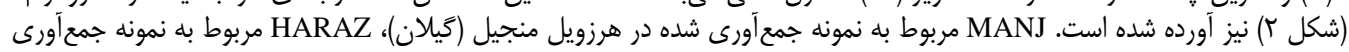
شده در جاده هراز، است.

Fig 1. 1\% Agaros Gel picture of (GA)8C-16 primer in 8 population of Juniperus spp. left column represents molecular marker and right column represent negative control. Abbreviation name also represent in Figure 2. MANJ represents those samples which were collected from Harzevel at Majil (Gilan), HARAZ represents those samples which were collected from Hraz road.

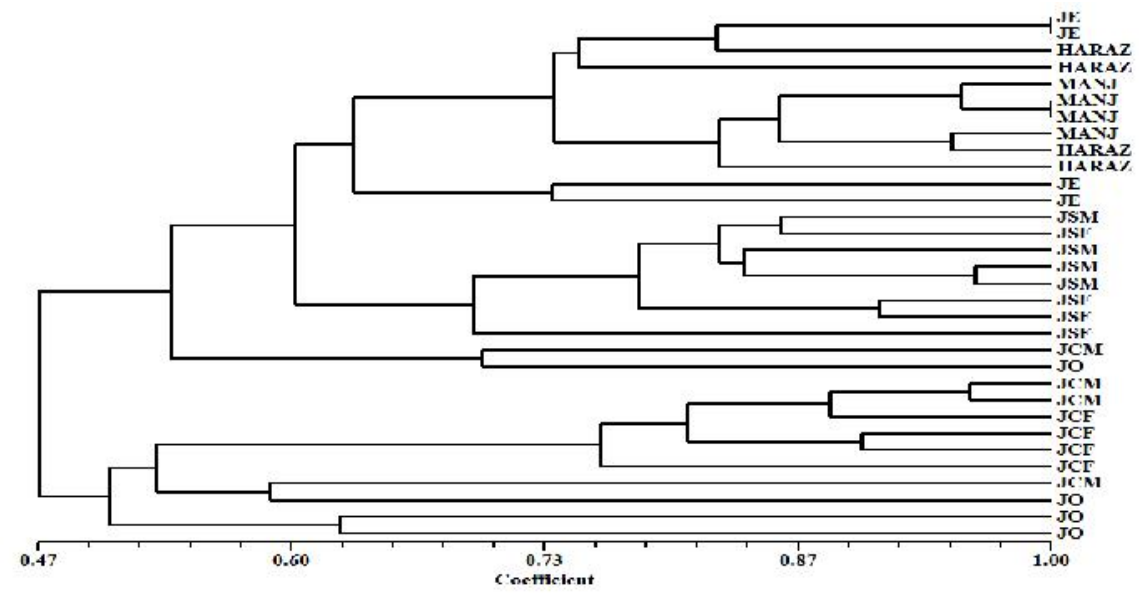

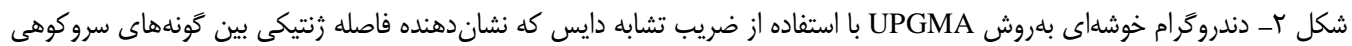

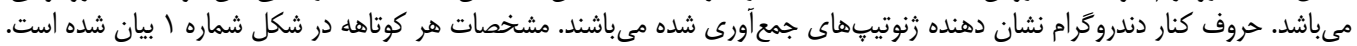
Figure 2. ISSR dendrogram based on Dice similarity indices, showing the genetic distance among Juniperus spp. The letters in the right side of the figure, represent collected Accessions. The full name of each abbreviation provided in Figure 1.

برخى از گونهها درون يك جمعيت در درون دسته دهاى ديخر

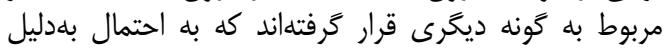

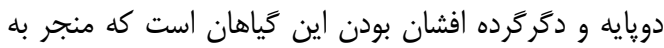

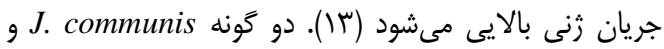

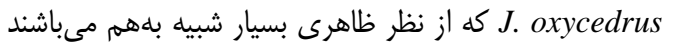
و از دو منطقه متفاوت در ارتفاعات توسكستان (سرييج

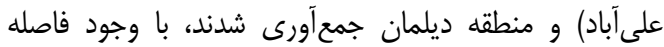

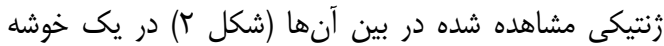

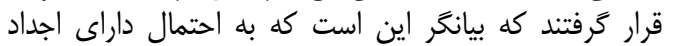

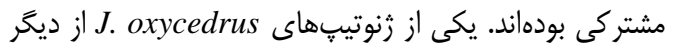

نتايج دندروگرام تا حد زيادى بيانگر اين است كه دو گَونه

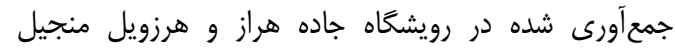

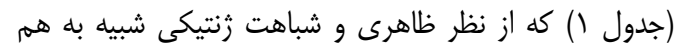

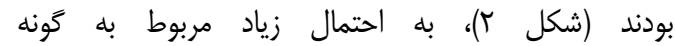
مى J. polycarpos

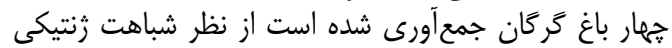

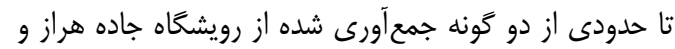

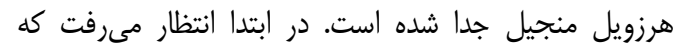

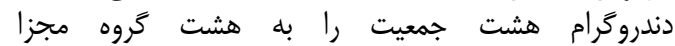
تقسيمبندى كند ولى نتايج متفاوت با اين انتظار بود. حتى 
در آمدهاند. جواب اين برسش منفى است. زيرا بر اساس نتايج

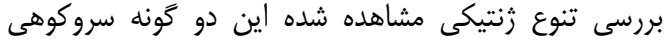

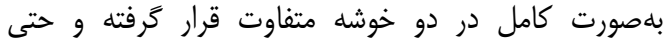

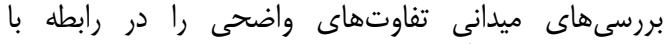

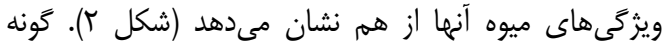
ج.excelsa

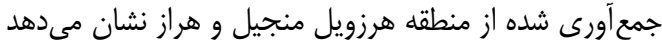

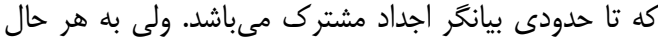

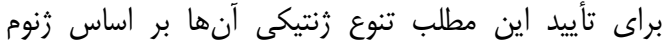

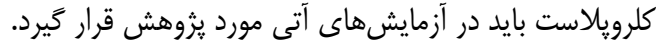

زرنوتيڤهاى موجود در همان جمعيت (تكرارهاى ديخر در

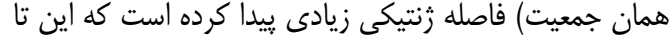

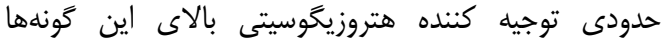

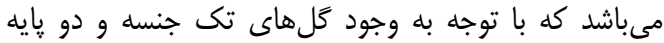

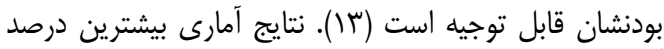

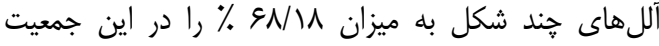

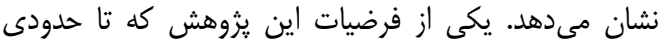

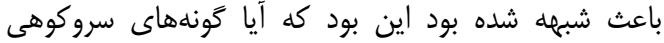

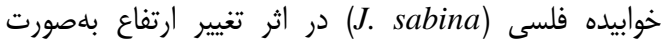
سروكوهى فلسى ايستاده (J.excelsa) در منطقه توسكسان

جدول س- تجزيه واريانس مولكولى نشانخر ISSR به دست آمده از هشت جمعيت سروكوهي Table 3. Analysis of molecular variance (AMOVA) in 8 Juniprues spp. populations

\begin{tabular}{|c|c|c|c|c|c|c|c|}
\hline$P$ Value & Value & وراريانس & واريانس & مريعاتخين & مربعات & آزادى & منابع تغيير \\
\hline \multirow[t]{3}{*}{$\cdot / \cdot .1$} & $\cdot / F \vee \Lambda$ & $+\wedge$ & $T / 1$. & $V^{*} / 1$. & $V \Delta / / \Delta$ & v & بين جمعيت \\
\hline & & $\Delta T$ & $r / \mu$. & $r / \mu$. & $\Delta \omega / \Gamma \Delta$ & re & داخل جمعيت \\
\hline & & $1 .$. & $F / F i$ & & $1 \pi \cdot / 4$. & ו & كل \\
\hline
\end{tabular}

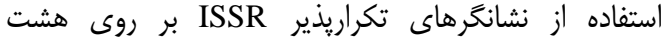

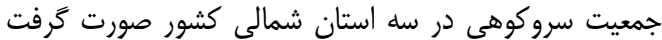

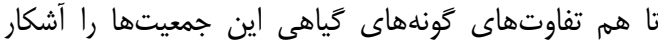

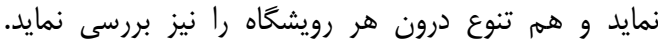

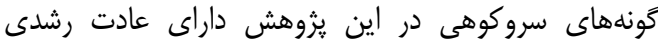

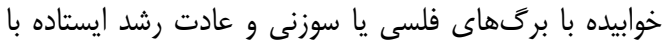

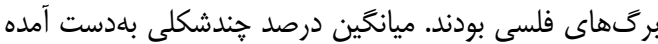

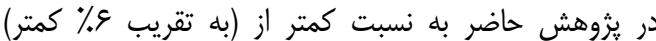

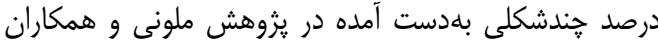

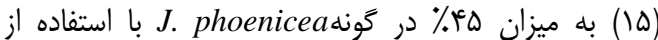

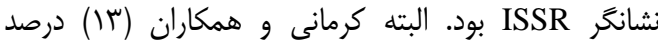

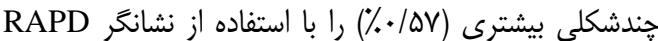

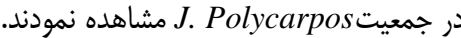

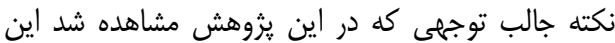

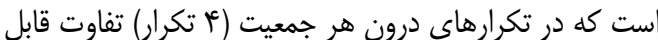

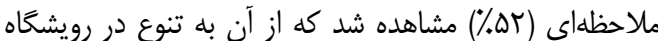

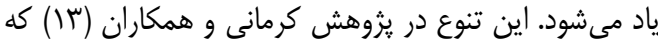

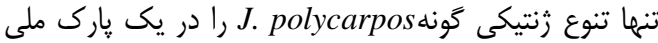

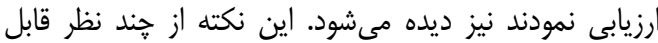

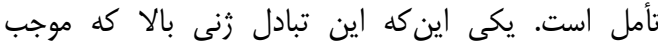

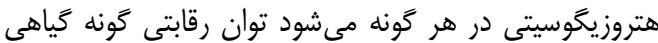

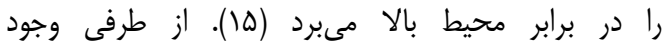

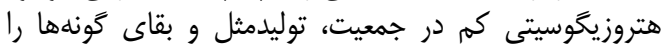

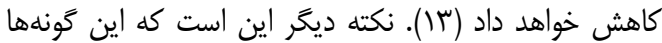

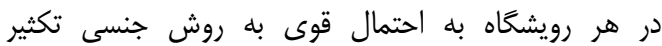

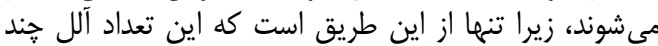

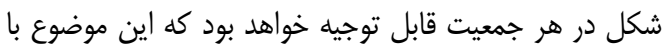

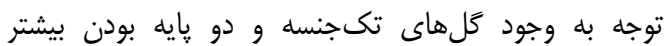

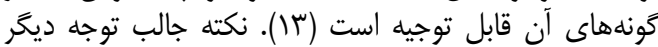

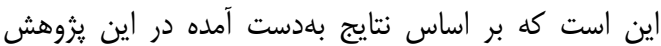

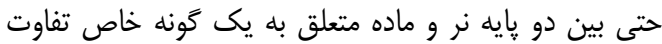

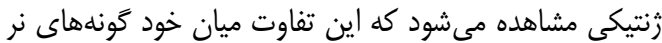

\section{تنوع درون و برون تَونهاى}

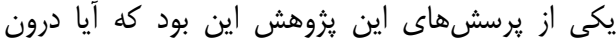

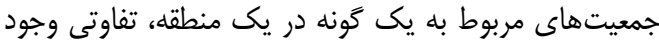

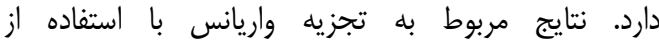

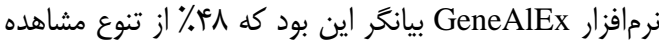

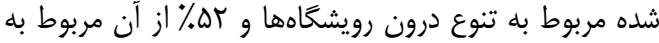

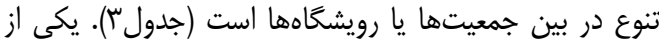

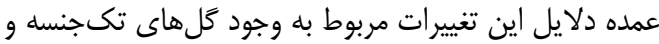

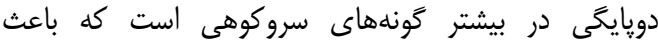

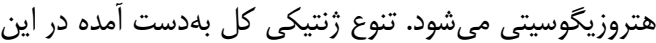

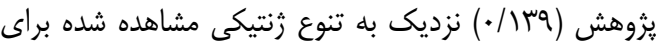

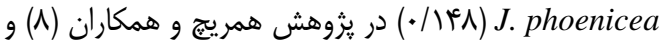

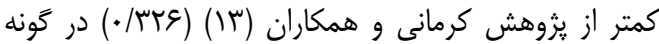

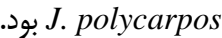

نياز شديد به حفاظت از بود بومسازگاه درختان به دليل

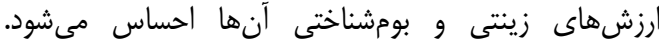

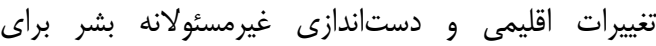

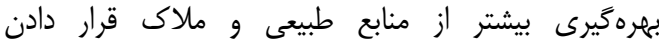

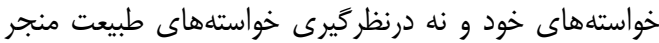

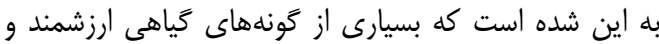

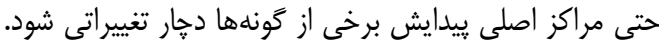

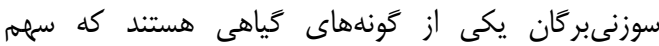

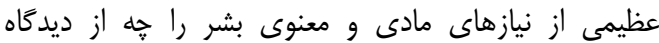

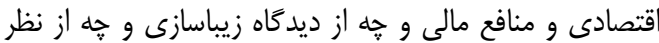
تأمين اكسيثن فراهم مى نمايندا.

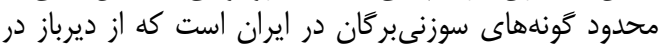

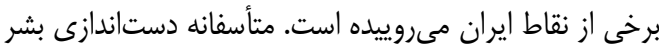

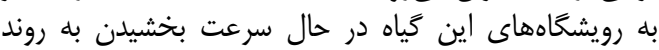

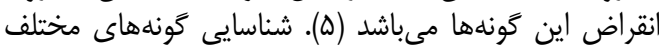

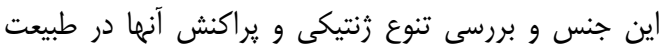

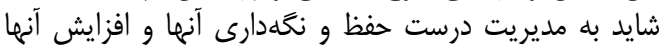

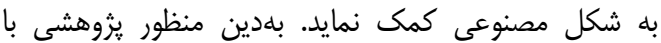


نتايج حاصل از ازدياد آنها را ممكن است به شدت متأثر نمايد.

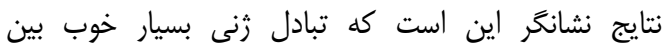

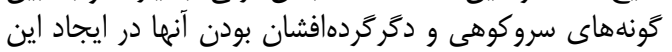

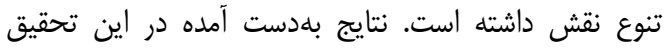

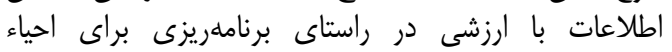

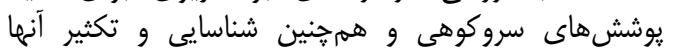

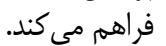

و يا ماده كمتر از تفاوت مشاهده شده بين نر و ماده مى مباشد.

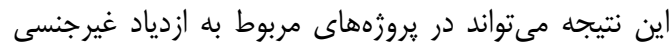

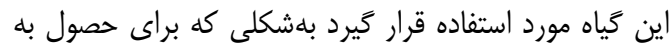

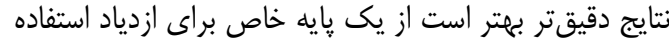

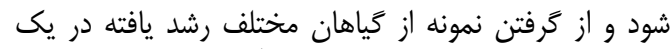

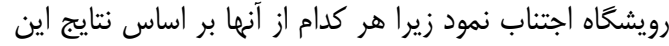

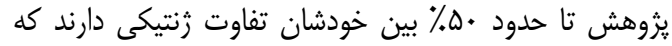

1. Adams, R.P. and F. Hojjati. 2012. Taxonomy of Juniperus in Iran: Insight from DNA sequencing. Phytologia, 94: 219-227.

2. Adams, R.P. 2011. Junipers of the World: the Genus Juniperus, 3rd edition. Trafford Publishing Co. Bloomington, IN, USA. p. 422

3. Adams, R.P., J.A. Morris, R.N. Pandey and A.E. Schwarzbach. 2005. Cryptic speciation between Juniperus deltoides and J. oxycedrus (Cupressaceae) in the Mediterranean. Biochemical Systematics and Ecology, 33: 771-787.

4. Daneshvar, A., M. Tigabu, A. Karimidoost and P. Christer Ode'n. 2017. Flotation techniques to improve viability of Juniperus polycarpos seed lots. Journal of Forestry Research, 28: 231-239.

5. Daneshvar, A., M. Tigabu, A. Karimidoost. and P. Christer Ode'n. 2016. Stimulation of germination in dormant seeds of Juniperus polycarpos by stratification and hormone treatments. New Forests, 47 : 751-761

6. Douaihy, B., G.G. Vendramin, A. Boratynski, N. Machon and M. Bu Dagher-Khayat. 2011. High genetic diversity with moderate differentiation in Juniperus excelsa from Lebanon and the eastern Mediterranean region. AoB PLANTS, plr003, doi:10.1093/aobpla/plr003.

7. Hampe, A. and R.J. Petit. 2010. Cryptic forest refugia on the 'Roof of the World'. New Phytologist 185: 5-7.

8. Hamrich, J.L., M.J.W. Goat and S.L. Sherman-Broyle. 1992. Factors influencing levels of genetic diversity in woody plant species, New Forest, 6: 95-124.

9. Hoffmann, D. and F.N. Hoffmann. 2003. Medical herbalism: The science and practice of herbal medicine. Healing Arts Press. 672 pp.

10. Hosseini, S.S. and V. Hosseini. 2014. Effect of Reforestation with Pinus nigra Arnold, Pinus eldarica Medw. and Cupressus arizonica Greene Spices on some Properties of Soil (Case Study: Garan region, Marivan). Ecology of Iranian Forest, 2: 37-44 (In Persian).

11. Jiménez, J.F., O. Werner, P. Sánchez-Gómez, S. Fernández and J. Guerra. 2003. Genetic variation and migration pathways of Juniperus thurifera L. (Cupressaceae) in the western Mediterranean region. Israel Journal of Plant Sciences 51: 11-22.

12. Kasaian, J., J. Behravan, M. Hassany, S.A. Emami, F. Shahriari and M.H. Khayyat. 2011. Molecular characterization and RAPD analysis of Juniperus species from Iran. Genetics and Molecular Research, 10: 1069-1074.

13. Kermani, M., A.H. Maraashi and F. Melati. 2009. Study of genetic variation of Juniperus polycarpus from Tandure National Park of Iran using RAPD markers. Rangelands and Forest Plant Breeding and Genetic Research, 18: 115-124 (In Persian).

14. Kumar, L.S., K. Tamura, I.B. Jakobsen and M. Nei. 2001. "MEGA2: Molecular evolutionary genetics analysis software". Bioinformatics, 17: 1244-1245.

15. Meloni, M., D. Perini, R. Filigheddu and G. Binelli. 2006. Genetic variation in five Mediterranean populations of Juniperus phoenicea as revealed by Inter-Simple Sequene Repeat (ISSR) markers. Annals of Botany, 97: 299-304.

16. Mozaffarian, V. 2009. Tree and shrubs of Iran. Farhang Moaser publication. 991pp (In Persian).

17. Silvia Pinna, M., O. Grillo, E. Mattana, E. Canadas and G. Bacchetta. 2014. Inter and intraspecific morphometric variability in Juniperus L. seeds (Cupressaceae). Systematics and Biodiversity, 12: 211-223.

18. Stange, C., D. Prehn and P. Arce-Johnson. 1998. Isolation of Pinus radiate genomic DNA suitable for RAPD analysis. Plant Molecular Biology Reporter, 16: 1-8. 


\title{
Evaluation of Junipers spp. Genetic Diversity in Northern Iran using ISSR Markers
}

\author{
Mostafa Khoshal Sarmast $^{1}$, Seyed Javad Mosavizadeh ${ }^{2}$ and Mehdi Sharifani ${ }^{3}$ \\ 1- Assistant Professor of Faculty of Plant Production, Gorgan University of Agricultural Sciences and Natural \\ Resources (Corresponding author: khoshhal.sarmast@ gmail.com) \\ 2 and 3- Assistant Professor and Associate Professor, Faculty of Plant Production, Gorgan University of Agricultural \\ Sciences and Natural Resources \\ Received: May 09, $2018 \quad$ Accepted: June 21, 2018
}

\begin{abstract}
The aim of the present work was to study genetic diversity within and among of five native populations of Juniperus spp. in three provenances of Golestan, Mazandran and Gilan. Four out of 15 ISSR primers have yielded 285 scorable, polymorphic fragments in 32 accessions, which were utilized to estimate genetic diversity. Analysis of molecular variance with GenALEx software revealed a $48 \%$ genetic diversity among Juniperus populations and $52 \%$ of molecular variance was observed within the populations. The mean percentage of polymorphic loci in each population estimated to be $38.64 \%$. Natural sexual propagation by seeds in each population likely is the main reason for the high rate of polymorphic loci. Another interesting issue is the genetic differences between male and female trees belong to one species which we should take into account during clonal propagation of designated juniperus species. The high rates of genetic variation within population which likely is associated with dioecy and presence of unisexual flowers in Juniperus species and also specific allelic combinations which could have been selected in order to adapt to particular environmental conditions are not present in other areas of distribution are prime importance for planning conservation strategies. By means of assessing the amount and distribution of genetic variability, this study represents an important step towards developing conservation guidelines and strategies for native Iranian Junipers.
\end{abstract}

Keywords: Juniperus, Molecular markers, Genetic diversity, Polymorphism, ISSR 